\title{
"Your Guide to Paediactric Anesthesia" by Sims and Johnson: A Book Review
}

\section{David Faraoni}

Department of Anesthesiology and Pediatric Anesthesia, Centre Hospitalier Universitaire Brugmann—HUDERF, Brussels, Belgium. Email: David.FARAONI@huderf.be

Received November $8^{\text {th }}, 2011$; revised December $10^{\text {th }}, 2011$; accepted December $19^{\text {th }}, 2011$

\begin{abstract}
"Your Guide to Paediatric Anaesthesia” by Sims and Johnson is the first edition of a book written for fellow or nonpediatric anesthetists. The authors give a practical approach for daily practice in pediatric anesthesia. This "book review" describes a general presentation and an objective evaluation of this recently published book.
\end{abstract}

Keywords: Book Review; Pediatric Anesthesia

\section{Introduction}

"Your Guide to Paediatric Anaesthesia” is the first edition of a new book talking about daily practice in pediatric anesthesia [1]. The authors have written this book with a main objective: be just as confident managing children as adults!

\section{Detailed Review}

This book reviews through 31 chapters general evidences for management of children scheduled to different types of surgeries. After some general information about preoperative preparation of the child and the family, the authors describe basic pharmacology of anesthetic agents. Then, common procedures are described, and basic upto-date recommendations are proposed. General considerations are exposed and basic practical guidelines are formulated for each field of pediatric surgery and anesthesia. Most of the routinely performed surgeries are reviewed, with some superficial considerations about more specific surgeries; as cardiac, thoracic, or neurosurgery.

This book written by the two practicing pediatric anesthesiologists from Australia is easy-to-read, descriptive, and exam focused. It gives safe, experience-based 'how to' approaches to pediatric and neonatal pathologies of both common and rare types. This book will provide the good information for anesthesia trainees to prepare examinations and for non-pediatric anesthetists the knowledge of contemporary pediatric anesthesia. Clean and readable layout with interesting illustrations is helpful, and the book also includes all the available past fellowship exam questions on pediatric topics in Australasian and United Kingdom.
The quality of the information in chapters about more specific condition could be considered superficial. In this field, some concerns could be formulated because the management description appears light. In chapter 5, information about fluid therapy does not describe the benefit to risk balance for the different solutions studied in the pediatric population. The same issues could be found in description of blood product transfusion, coagulation, and bleeding management. The information in the chap- ter about regional anesthesia could have been written with more clinical detail. Non-specialists would wish to find more detailed recommendation to guide their options in local anesthetics and the dosage, and techniques available for each type of surgery. Overall, specialists in pediatric anesthesia would probably consider this book as too basic, and we could suppose that in case of second edition, authors will improve their approach of some pathologies and conditions.

Nevertheless, this book presents the basic knowledge and practical information we need to get the most out of our precious pediatric training time.

In conclusion, this book is recommended for trainees and non-pediatric anesthetists who require a "cook-book" to prepare their pediatric anesthesia or review basic information before an exam.

\section{REFERENCES}

[1] C. Sims and C. Johnson, "Your Guide to Paediactric Anesthesia,” McGraw-Hill Professional, McGraw-Hill Professional Australia Pty Ltd, North Ryde, 2011. 